\title{
Standards for European training requirements in interventional neuroradiology
}

\author{
Guidelines by the Division of Neuroradiology/Section of Radiology European Union of Medical \\ Specialists (UEMS), in cooperation with the Division of Interventional Radiology/UEMS, the \\ European Society of Neuroradiology (ESNR), and the European Society of Minimally Invasive \\ Neurological Therapy (ESMINT)
}

Marek Sasiadek ${ }^{1}$ - Naci Kocer ${ }^{2}$ - Istvan Szikora ${ }^{3}$ - Pedro Vilela ${ }^{4}$ - Mario Muto ${ }^{5}$ - Olav Jansen ${ }^{6}$ - Francesco Causin ${ }^{7}$. Christophe Cognard ${ }^{8}$. Phil White ${ }^{9}$. Patrick A. Brouwer ${ }^{10}$. Francesca B. Pizzini ${ }^{11}$. Gerhard Schroth ${ }^{12}$ • Paolo Ricci ${ }^{13}$

Published online: 1 November 2019

(C) The Author(s) 2019

\begin{abstract}
This document sets out standards for training in Interventional Neuroradiology (INR) in Europe. These standards have been developed by a working group of the European Society of Neuroradiology (ESNR) and the European Society of Minimally Invasive Neurological Therapy (ESMINT) on the initiative and under the umbrella of the Division of Neuroradiology/Section of Radiology of the European Union of Medical Specialists (UEMS).
\end{abstract}

Keywords Standards

\section{Foreword}

This document sets out standards for training in Interventional Neuroradiology (INR) in Europe. These standards have been developed by a working group of the European Society of
Neuroradiology (ESNR) and the European Society of Minimally Invasive Neurological Therapy (ESMINT) on the initiative and under the umbrella of the Division of Neuroradiology/Section of Radiology of the European Union of Medical Specialists (UEMS). For the current document, the

Marek Sasiadek, Naci Kocer and Istvan Szikora contributed equally to this work.

This article is co-published in the journals Neuroradiology and Journal of NeuroInterventional Surgery. https://doi.org/10.1007/s00234-01902300-2 or https://doi.org/10.1136/neurintsurg-2019-015537

Naci Kocer

nkocer@istanbul.edu.tr

$\triangle$ Istvan Szikora

h13424szi@ella.hu

1 Wroclaw Medical University, Wroclaw, Poland

2 Istanbul University, Cerrahpasa Medical Faculty, Istanbul, Turkey

3 National Institute of Clinical Neurosciences and Semmelweis University, Budapest, Hungary

4 Beatriz Angelo Hospital, Lisbon, Portugal

5 Azienda Ospedaliera Antonio Cardarelli, Napoli, Italy
6 Christian-Albrechts-Universität zu Kiel, Kiel, Germany

7 Azienda Ospedaliera di Padova, Padova, Italy

8 Centre Hospitalier Universitaire de Toulouse, Toulouse, France

9 Newcastle University \& Newcastle Hospitals NHS Trust, Newcastle upon Tyne, UK

10 Karolinska University Hospital, Stockholm, Sweden

11 Azienda Ospedaliera Universitaria Integrata Verona, Verona, Italy

12 University of Bern, Inselspital, Bern, Switzerland

13 Azienda Ospedaliero-Universitaria Policlinico Umberto I, Sapienza Università di Roma, Roma, Italy 
text of guidelines proposed and published earlier by the previous Board of UEMS's Division of Neuradiology $[1,2]$ was used and modified with the consensus of all involved parties.

It is well recognized that there are a number of structural and operational differences in the health care systems, appointment procedures, and training systems in the various European countries. This document takes into consideration the health system and demographic realities of Europe.

Presently, the national laws in each of the EU Member States regulate the professional activity of each country. In this context, it is important to build a comprehensive INR core curriculum and training program that can be used in the individual countries according to their organization and laws, and that complies with international treaties, the UN Declarations on Human Rights, and the WMA International Code of Medical Ethics.

The INR curriculum should constitute a uniform training program, approved by all the European countries, which can be incorporated in pre-existing national programs or serve as the basis for the development of new programs, according to the national regulations.

In this document, the INR training program will be referred to as "particular qualification" in INR.

Currently, a significant number of specialists in Europe are performing all or some of the INR activities detailed in this Training Charter. These specialists will have the acquired right to continue this practice.

This document is complemented with another, the "Standards of Practice in Interventional Neuroradiology. Consensus document from the UEMS/ESMINT/ESNR" [3]

\section{Article 1: Goal of the training program}

This document provides the basis for the development of a harmonized, comprehensive, structured, and balanced European training program in INR.

\section{The primary goal}

The primary goal of an INR training program is to provide the trainee with a broad knowledge base, the procedural skills and experience, professional judgment, and self-criticism required to safely practice INR.

\section{Definition and scope of interventional neuroradiology}

Interventional neuroradiology uses percutaneous and/or endovascular procedures to treat patients with diseases of the brain, sensory organs, head and neck, spinal cord, vertebral column, and adjacent structures and the peripheral nervous system, both in adults and in children.

\section{General rules on monitoring and accreditation}

\section{Monitoring authority}

National professional licensing bodies (responsible for recognition of medical specialists in individual countries) may recognize INR training programs using the standards of this training charter.

\section{Accreditation of the training program}

- National professional licensing bodies, or in their absence, a European association/society/organization (UEMS or European subspecialty Societies-e.g., ESNR, ESMINT, or Boards cooperating with UEMS) should provide a general program for accrediting teaching institutions. This is a voluntary procedure aimed at securing high-quality and good standards of practice in the teaching programs. It is recommended that this accreditation process be valid for a limited time and be renewed on a regular basis, according to the national regulations.

- Accreditation to train the candidates within an INR program can only be granted or renewed if the applying program documents a minimum annual activity as defined in paragraph 4.1. The accrediting authority for each applying institution may define an agreed intermediate level of activity.

- The teaching program should be established within a clinical neuroscience institution, or a network of such institutions, with all the appropriate related specialties represented.

- The institution's patient population must have a diversity of illnesses (brain, head and neck, spine) from which a broad experience in INR can be obtained.

- The director of the training program should meet the requirements stated at point 5.1. of the Charter, in particular he/she should be "an active interventional neuroradiologist and seek or needs (if available) the national accreditation of the program by a national authority or the respective national neuroradiological professional association."

\section{Article 2: General aspects of training in interventional neuroradiology}

\section{Selection criteria and access to the particular INR qualification}

2.1.1 Trainees must have a valid license to practice medicine within their respective countries; this license must be recognized by the country/countries where training is to take place.

2.1.2 Trainee selection criteria should be defined at a national level according to national medical regulations. It is 
required that before entering INR training, trainees should be qualified physicians in a training program of a medical specialty or have accomplished training in a recognized medical specialty.

2.1.3 After appointment of a trainee, an individualized training program stipulating the relationships, duties, and obligations of each party should be formulated and signed by the director of the program and the trainee.

2.1.4 Training could be limited to a specific area of INR, e.g., spinal interventions or endovascular treatment of ischemic stroke, including the management of complications; provided that the minimum annual activity for the specific area as defined in 4.1 is fulfilled and site conditions and operational guidelines are guaranteed by the training institution, according to the UEMS/ESNR/ESMINT consensus document for standards of practice in Interventional Neuroradiology [3].

\section{Duration and content of education and training}

- The overall purpose of training in INR is to reach the predefined goals set out in this Training Charter.

- The education and training needed to become a specialist physician with particular qualification in INR consists of:

- 12 months mandatory dedicated training in diagnostic neuroradiology

- 24 months mandatory dedicated training in INR

- 12 months recommended clinical training in neuroscience

- Depending on previous training, these durations may be reduced as credit is given for previous training and clinical skills. Assessment of previous training and clinical skills, and evaluation of the remaining training time is the responsibility of the director and each of the co-directors of the program after thorough and careful assessment of proven previous training and experience.

- In case of training that is limited to specific areas of INR, such as endovascular treatment of ischemic stroke (as listed in article 2.1.4), the requirements of existing multisociety global recommendations (such as the "Training Guidelines for Endovascular Ischemic Stroke Intervention: An International Multi-Society Consensus Document" [4] and the "Standards of practice in acute ischemic stroke intervention: international recommendations" [5] should be applied. The program and the training/educational facility must fulfil the criteria detailed in points 4 and 5 of this document.

- The UEMS cooperating European Board is the governing body to handle appeals and complaints.
Curriculum of general and specific training periods

\section{Training curriculum}

The training curriculum, designed to provide a diversified, balanced mix of theoretical and practical education in INR, describes the contents and aims of the program. In the individual training program, emphasis should be placed on adequate time allocated for study, independent of clinical duties. It may be necessary for some programs to formally organize specific training periods in associated diagnostic or clinical therapeutic units, if adequate experience cannot be organized internally.

\section{Network of institutions}

A training program is based on a pre-organized network of accredited institutions/departments, coordinated by the program director when rotation periods in these institutions/ departments are necessary. These rotations should be organized in such a way as to give trainees guaranteed training in accordance with the curriculum.

\section{Trainee portfolio-CV}

Trainees should keep a trainee portfolio, containing details of previous training posts, examinations passed, lists of publications and presentations at meetings, courses attended, cumulative procedural totals, and copies of assessment forms from the different training periods.

\section{Article 3: Specific aspects of training in interventional neuroradiology}

\section{Educational and training program}

\section{General objectives and goals of training}

Ideally, interventional neuroradiology should be practiced in INR teams where exchange of experience, knowledge, and research findings is possible. Having finished the training program, the specialist physician with particular qualification in INR, will be able to perform endovascular and percutaneous procedures as described in Art 4 in a team with other interventional neuroradiologists. Solitary practice of INR is not recommended.

A specialist physician with particular qualification in INR shall:

- Have acquired knowledge in basic and clinical neuroscience, including skull anatomy, head and neck anatomy, spinal anatomy, cranial and peripheral nerve anatomy, 
neuroanatomy, neurobiology, and pathology and natural history of neurological and other neuroradiologicalrelated disorders

- Have the skill to consult and communicate with referring physicians, patients, and their relatives

- Have the skill and knowledge to independently perform, conduct, and interpret common endovascular/ percutaneous INR procedure

- Master the diagnostic and therapeutic methods used within the domain of INR and be aware of their development, strengths, weaknesses, and risks

- Advise other clinicians and carry the main responsibility for how diagnostic and therapeutic methods are used within the domain of INR

Research should be encouraged, and time and facilities should be made available for this purpose during training.

\section{Knowledge-based objectives}

Unless otherwise defined, all points below are defined in relation to diseases of the central and peripheral nervous system, the head and neck area, and the spine.

\section{Basic neuroscience}

- Neuroanatomy/head and neck anatomy/spine anatomyincluding embryology and functional anatomy

- The focus is on arterial and venous functional anatomy of the brain, skull, head and neck, and spine.

- In embryology, the focus is on vascular embryology of the brain, head and neck, and spine.

- Biomechanics of the spine.

- Neurobiology - including genetics and an overview of molecular biology

- Neurophysiology and biology of pain mechanisms and the biopsychosocial implications.

- Pathology: the full spectrum of vascular diseases, including inflammatory and autoimmune diseases.

- Natural history of neurovascular diseases

\section{Clinical training}

- Epidemiology

- Clinical history and patient assessment

- Symptomatology

- Clinical neurologic examination

- Communication:

- Discuss the indications and contraindications for diagnostic and interventional procedures
- Appropriately report diagnostic and interventional procedures

- Consult and communicate with other clinicians

- Participate in and conduct regular clinical rounds and conferences

- Communicate with residents in training

- Communicate with patients and their relatives

- Communicate with the hospital staff and administration

- Participate in quality control programs

\section{Therapeutics-general aspects}

- Selection and interpretation of ancillary tests necessary for establishing the diagnosis, indications, treatment plan, and follow-up.

- Selection of treatment options (indications and contraindications) must be based on knowledge and communication in a multidisciplinary environment.

- Pre- and post-procedural management

- Immediate preoperative diagnostic work-up

- Patient preparation before procedure

- Postoperative maintenance of physiological equilibrium

- Management of hospital discharge (documentation, communication, coordination, and reports)

- Organization of follow-up procedures.

- Clinical neuropharmacology

- Knowledge in pharmacology, including drug interactions

- Pre- and postoperative usage of drugs

- Knowledge in neurointensive care

\section{Imaging technology and radiation}

- Mastering the physiological, technical, mathematical, and statistical principles, and the strengths and weaknesses of common neuroradiological diagnostic and interventional procedures.

- Knowledge about radiation physics

- Radiation biology

- in diagnostic neuroradiology and INR

- in radiotherapy and radiosurgery

- Radiation protection in diagnostic neuroradiology and INR and knowledge of the laws governing the use of medical radiation

- Patient protection

- Staff protection 
Clinical neuroradiology Training in clinical neuroradiology should not only focus on diseases related to INR but also should provide a general understanding and overview of common diseases and conditions related to the field of neuroradiology.

- Knowledge related to technical aspects of clinical neuroradiology including digital subtraction angiography, computed tomography, magnetic resonance imaging, and ultrasound

- Selection of optimal diagnostic procedures using knowledge of the indications, contraindications, and limitations of diagnostic neuroradiology procedures

- Ability to understand diagnostic neuroradiological procedures as they relate to INR

- Knowledge and management regarding all aspects of contrast materials, including interactions and complications, as they are used in clinical neuroradiology and INR.

\section{Therapeutics - specific objectives}

- Pre- and post-procedure management

- Explaining the risks and benefits of a planned therapeutic strategy to the patient (informed consent)

- Proposed and alternative therapies

- Immediate preoperative diagnostic work-up

- Patient preparation before the INR procedure

- Organization of clinical follow-up and diagnostic procedures

- Clinical neuro-pharmacology

- Contrast agents

- Blood pressure control medications

- Seizure medication

- Analgesic and sedative medications

- Peri-procedure drug usage, including interactions

- Anticoagulant, antiplatelet and thrombolytic therapies

- Anti-vasospasm drugs

- Acquisition of skills and experience in INR procedures

- Establishing an individual treatment strategy

- Aim of INR therapy

- Defining the therapeutic goal

- Establishing the procedure priorities and steps

- Defining the optimal treatment strategy and technical performance

- Considering possible treatment complications and risks
- Pre-procedure briefing of the staff and ancillary staff regarding the treatment plan

- Technical and strategic components

- Percutaneous access to the vascular system, the head and neck compartments, and the spine

- Usage of delivery systems: needles, catheters, wires, and rinsing systems, and medical devices for the abovementioned core INR clinical activity

- Skillful management of radiological equipment in INR

- Post-procedure management of the puncture site

- Procedure risks and limitations

- Complication management

- INR technical experience attained

- Percutaneous treatments

Each trainee must have performed 50 spine procedures as first operator, including a case mix of disk treatments, epidural spine treatments, nerve blocks, facet joint treatments, and vertebral bone augmentation treatments

- Neuro-endovascular procedures

Each trainee must have performed 100 digital subtraction angiograms as first operator before starting endovascular interventional procedures

Each trainee must have participated in a minimum of 150 endovascular INR procedures, of which in at least in half of the procedures the trainee was the principal operator. The diversity of these procedures should include endovascular treatment of aneurysms, acute ischemic stroke, extracranial and intracranial angioplasty/stenting, embolization of brain AVM and dural AVF, and external carotid embolization.

Each trainee must have participated in a minimum of 50 cases of revascularization and 50 cases of embolization (in either group in at least half of the procedures as the principal operator).

If the trainee did not complete the required number of procedures during the training period, the INR training must be prolonged accordingly.

\section{Attitude and ethics in INR}

- Be able to make independent and well-founded decisions in medical ethical matters within INR

- Prioritize and optimize the use of resources

- Understand implications and priorities in the management of incidentally discovered or associated lesions

- Manage medical risks and incidents 
- Understand medical legal implications pertaining to INR

- Participate in regular departmental and interdisciplinary conferences including regular reviews of patient morbidity and mortality, and if developed, critical incident reporting systems (CIRS)

- Participate in INR national or international quality assurance programs is strongly recommended

- Participate in national and international courses and meetings (a minimum of 2 weeks/year during training)

- Obtaining the European Diploma in Neuroradiology is highly recommended

\section{Research}

- The educational environment should encourage trainees to undertake investigative study in relevant clinical or basic science subject areas.

- Trainees can participate in research projects conducted by the faculty or other trainees, or can undertake projects as principal investigators.

- Trainees should have a firm knowledge of the fundamentals of the experimental design, performance, and interpretation of results.

- Trainees should have basic knowledge of medical statistics.

- Trainees should be encouraged to submit their work for presentation at national or international meetings and to publish in scientific journals.

- Trainees should understand ethical aspects and what constitutes a conflict of interest.

\section{Training log-book and periodic assessment of trainee progress}

\section{Log-book during INR training}

Each trainee must keep a personal log-book for documentation of the skills acquired and experience performing procedures. The log-book should be based on the PACS and RIS system of the clinic, including the information, if the trainee acted under supervision or self-responsible. Trainees will have to demonstrate that they have participated in a wide spectrum of INR procedures (See 3.1.2.6. Therapeutics — specific objectives), which should include a balance of supervisor-assisted procedures and procedures performed personally under supervision. Log-book entries must be monitored by regular inspection and signed by the appropriate supervisor. The log-book must be available at the Board examination and other summative examinations.

\section{Evaluation of trainees}

The program director, in consultation with the co-directors and faculty, will evaluate the qualification and progress of each trainee at least twice a year. The evaluation includes assessment of the trainee's knowledge, technical skills, attitudes and interpersonal relationships, decision-making skills, and clinical management skills. These evaluations should be documented, given to the trainees, and discussed with them. The program director, in agreement with the co-directors, certifies the competence of trainees at completion of training.

Trainees must have the opportunity to provide a documented evaluation of the program and faculty at least once annually.

The evaluation must be approved by the UEMS cooperating European Board.

The EBSQ examination is a specific system developed by the UEMS NR Division in agreement with the UEMScooperating bodies involved in the ETR, whose examinations are specifically built for evaluation of general knowledge required for neurointerventional.

The evaluation of the trainees by the program director/co-directors should be structured in the following order:

\section{A. Knowledge}

1. Knows of

2. Knows basic concepts

3. Knows generally

4. Knows specifically and broadly

B. Clinical skills

1. Has observed - the trainee acts as an "Assistant." From complete novice through to being a competent assistant.

At end of level 1, the trainee:

a. Has adequate knowledge of the steps through direct observation.

b. Demonstrates that he/she can handle instruments relevant to the procedure appropriately and safely.

c. Can perform some parts of the procedure with reasonable fluency.

2. Can do with assistance - a trainee is able to carry out the procedure "Directly Supervised." From being able to carry out parts of the procedure under direct supervision, through to being able to complete the whole procedure under lesser degrees of direct supervision (e.g., trainer immediately available). 
At the end of level 2, the trainee:

a. Knows all the steps - and the reasons that lie behind the methodology.

b. Can carry out a straightforward procedure fluently from start to finish.

c. Knows and demonstrates when to call for assistance/ advice from the supervisor (knows personal limitations).

3. Can do the whole procedure but may need assistance- - a trainee is able to do the procedure "indirectly supervised." From being able to carry out the whole procedure under direct supervision (trainer immediately available) through to being able to carry out the whole procedure without direct supervision, i.e., trainer available but not in direct contact with the trainee.

At the end of level 3, the trainee:

a. Can adapt to well-known variations in the procedure encountered, without direct input from the trainer.

b. Recognizes and makes a correct assessment of common problems that are encountered.

c. Is able to deal with most of the common problems.

d. Knows and demonstrates when he/she needs help.

e. Requires advice rather than help that requires the trainer to scrub.

4. Competent to do without assistance, including complications. The trainee can deal with the majority of operative problems and complications, but may need occasional help or advice.

5. Can be trusted to carry out the procedure, independently, without assistance or need for advice.

At the end of level 5, the trainee:

a. Can deal with straightforward and difficult cases to a satisfactory level and without the requirement for external input to the level at which one would expect a consultant INR to function.

b. Is capable of instructing and supervising trainees.

A. Technical skills

1. Has observed.

2. Can do with assistance.

3. Can do whole but may need assistance.

4. Competent to do without assistance, including complications, but may need advice or help.

5. Can be trusted to carry out the procedure, independently, without assistance or need for advice (EPA)
Article 4: Requirements for training institutions/departments

\section{Requirements regarding equipment and educational facilities}

The optimal training program in INR must take place and be organized in a single institution or in a network of institutions/ departments in which the INR unit is core and is surrounded by clinical and diagnostic neuroscience units, and operating in accordance with the "Standards of Practice in Interventional Neuroradiology. Consensus document from the UEMS/ESMINT/ESNR" [3].

To qualify as a training program, the following conditions must be fulfilled:

- The director and co-directors must have senior appointments in a recognized training institution that may be affiliated with academic institutions. Commercial interests cannot be involved in the organization and scientific content of the training.

- Ideally, the network should be involved in active INR research.

- There should be ready access to general medical/ neurointerventional texts and scientific journals. Computerized literature search facilities should be available.

- The INR core must fulfil the following conditions:

- INR case load of a minimum of 100 cases/year of endovascular interventions and 50 cases/year of percutaneous spinal interventions. INR case mix should include a diversity of vascular diseases, such as acute ischemic stroke, aneurysms, AVMs, DAVFs, and spinal vascular malformations, in the respective percentages according to their prevalence. If accreditation is limited to percutaneous spinal interventions, the minimum case load is 50 cases/ year. If accreditation is limited to endovascular treatment of ischemic stroke, the minimum case load is 50 cases/year.

- The faculty of the training program must include at least two members practicing INR.

- The proportion of INR trainers to trainees must not exceed a 1:1 ratio

\section{Article 5: Requirements for the training program director and faculty}

\section{Criteria for program director, co-directors, and faculty}

The director of a training program must be an active interventional neuroradiologist certified according to the national 
regulations, or in their absence by the UEMS cooperating European Board.

- The program director may have a senior academic appointment or a senior leading position as an interventional neuroradiologist in a non-profit training institution.

- The program director coordinates the network that constitutes the training program.

- A network co-director should be well experienced and well respected as an interventional neuroradiologist or as a medical specialist in another appropriate specialty, i.e., radiology, neuroradiology, neurosurgery, or neurology.

- A director or co-director should participate in appropriate $\mathrm{CME} / \mathrm{CPD}$ activities accordingly to the national regulations.

- The program director and co-directors in agreement are responsible for enforcing the Training Charter, and for selecting and supervising the trainee and faculty members.

- The program director is expected to ensure that the program meets the required academic standard.

- The program director should seek or needs (if available) the national accreditation of the program by a national authority or the respective national neuroradiological professional association.

\section{Article 6: Certification of particular qualification}

The national or regional medical authority is the body responsible for official recognition and certification of the particular qualification in each country.

The program director is responsible for obtaining certification of the training and acquiring particular qualification, which is dependent on a properly executed accreditation and visitation process defined at a national level or provided by UEMS.

A final board examination will be organized by UEMS or approved by UEMS. The achievement of UEMS-CESMA appraisal will be considered a quality element for the use of an exam produced by a UEMS cooperating body.

\section{Article 7: Maintenance of competence}

Maintenance of a particular qualification in INR is subject to the general principles of the "Standards of Practice in Interventional Neuroradiology," a consensus document by UEMS, ESMINT, and ESNR [3] that is a revised version of a paper published earlier by Jansen et al. [6].
Authors contribution Authors of this paper contributed on behalf of the following organizations:

Marek Sasiadek, Francesca B. Pizzini, Gerhard Schroth on behalf of the Divison of Neuroradiology, European Union of Medical Specialists (UEMS).

Naci Kocer, Pedro Vilela, Mario Muto, Olav Jansen, Francesco Causin on behalf of the European Society of Neuroradiology (ESNR).

Istvan Szikora, Christophe Cognard, Phil White, Patrick A. Brouwer on behalf of the European Society of Minimally Invasive Neurolgoical Therapy (ESMINT).

Paolo Ricci on behalf of the Section of Radiology, European Union of Medical Specialists (UEMS)

\section{References}

1. Specialists, E.U.o.M. (2012) UEMS recommendations for acquiring "Particular qualification" in Endovascular Interventional Neuroradiology - INR. EJMINT

2. Flodmark O, Grisold W, Richling B, Mudra H, Demuth R, Pierot L (2012) Training of future interventional neuroradiologists: the European approach. Stroke 43(10):2810-2813

3. UEMS (2019) Standards of Practice in interventional neuroradiology. Consensus document from the ESNR/ESMINT/UEMS. https:// neuro.uemsradiology.eu/app/uploads/SoP-in-INR.pdf. Accessed 27 Oct 2019

4. Lavine SD, Cockroft K, Hoh B et al (2016) Training guidelines for endovascular ischemic stroke intervention: an international multisociety consensus document. AJNR Am J Neuroradiol

5. Pierot L, Jayaraman MV, Szikora I, Hirsch JA, Baxter B, Miyachi S, Mahadevan J, Chong W, Mitchell PJ, Coulthard A, Rowley HA, Sanelli PC, Tampieri D, Brouwer PA, Fiehler J, Kocer N, Vilela P, Rovira A, Fischer U, Caso V, van der Worp B, Sakai N, Matsumaru Y, Yoshimura SI, Anxionnat R, Desal H, Biscoito L, Pumar JM, Diaz O, Fraser JF, Linfante I, Liebeskind DS, Nogueira RG, Hacke W, Brainin M, Yan B, Soderman M, Taylor A, Pongpech S, Tanaka M, Terbrugge K, Asian-Australian Federation of Interventional and Therapeutic Neuroradiology (AAFITN), Australian and New Zealand Society of Neuroradiology (ANZSNR), American Society of Neuroradiology (ASNR), Canadian Society of Neuroradiology (CSNR), European Society of Minimally Invasive Neurological Therapy (ESMINT), European Society of Neuroradiology (ESNR), European Stroke Organization (ESO), Japanese Society for NeuroEndovascular Therapy (JSNET), French Society of Neuroradiology (SFNR), Ibero-Latin American Society of Diagnostic and Therapeutic Neuroradiology (SILAN), Society of NeuroInterventional Surgery (SNIS), Society of Vascular and Interventional Neurology (SVIN), World Stroke Organization (WSO), World Federation of Interventional Neuroradiology (WFITN) (2018) Standards of practice in acute ischemic stroke intervention: international recommendations. AJNR Am J Neuroradiol 39(11):E112-E117

6. Jansen O, Szikora I, Causin F, Brückmann H, Lobotesis K (2017) Standards of practice in interventional neuroradiology. Neuroradiology 59(6):541-544

Publisher's note Springer Nature remains neutral with regard to jurisdictional claims in published maps and institutional affiliations. 